\section{A technical issue with CanMEDS}

To the Editor: The ultimate objective of surgical training is to produce competent surgeons capable of meeting the health care needs of our society. Surgical training programs tend to emphasize the achievement of cognitive, professional and technical competence. The recent article by Mickelson and MacNeily' provided an important and comprehensive approach on how urology training programs can integrate the assessment of the core competency domains outlined in the Canadian Medical Education Directives for Specialists (CanMEDS) initiative. It also highlighted a critical shortcoming of CanMEDS as it is applied to surgery. Despite the importance of a good foundation of surgical skill, technical competence has historically been ill-defined and consequently poorly assessed. ${ }^{2}$ Using CanMEDS as an example, technical competence is not defined explicitly, but is hidden among definitions of the other core competencies under nonspecific subcategories like "medical expert - demonstrates proficient and appropriate use of procedural skills, both diagnostic and therapeutic." ${ }^{\prime 3}$ This clearly does not do surgical educators, evaluators or trainees justice. As a surgical community, we must continue to strive toward the discovery and application of valid and reliable assessments of technical skill. The Objective Structured Assessment of Technical Skills (OSATS) on simulators in the skills lab is an important start. The time has come, however, for intraoperative evaluations of competency linked to patient outcomes.

\section{Ethan D. Grober, MD, Med, FRCSC}

Assistant Professor, Division of Urology, University of Toronto, Murray Koffler Urologic Wellness Centre, Mount Sinai Hospital, Toronto, Ont.

\section{References}

1. Mickelson JJ, MacNeily AE. Translational education: tools for implementing the CanMEDS competencies in Canadian urology residency training. CUAJ 2008;2:395-404.

2. Grober ED, Jewett MA. The concept and trajectory of "operative competence" in surgical training. Can I Surg 2006;49:238-40.

3. Royal College of Physicians and Surgeons of Canada. CanMEDS 2005 framework. Available: htrtp://rcpsc.medical.org/canmeds/bestpractices/framework_e.pdf (accessed 2008 Sept 4).

\section{Author's reply}

The goal of Canadian urology residency training programs is to produce competent urologic surgeons. As Dr. Grober highlighted, CanMEDS competencies can fall short in the assessment of technical skills. Surgical competence is not explicitly highlighted as an "expected competency" and is part of the hidden curriculum within the competencies of "medical expert." Although, development of "operative competence" requires a symbiosis of cognition, communication, collaboration and technical ability, there are discrete technical skills that must be mastered. ${ }^{1}$ Dr. Grober correctly asserts that making technical surgical skills training explicit and developing valid and reliable assessments of technical skills is paramount to urology training. The OSATS, using both low-fidelity and high-fidelity training opportunities as residents progress through residency, are a sound stepping stone to surgical competence. As a validated and reliable tool, the OSATS are a useful tool in the armamentarium of assessment. ${ }^{2}$ We agree that the time has come for intraoperative assessment of technical competence based on standardized and validated measures.

\section{Jennie Mickelson, MD, FRCSC}

Pediatric Urology Fellow, Children's Memorial Hospital,

Northwestern University, Chicago, III.

\section{Andrew MacNeily MD, FRCSC, FAAP}

Division Head, Pediatric Urology Associate Professor and

Program Director, Department of Urological Sciences, University of British Columbia, Vancouver, BC

\section{References}

1. Grober ED, Jewett MA. The concept and trajectory of "operative competence" in surgical training. Can I Surg 2006;49:238-40.

2. Martin JA, Regehr G, Reznick R, et al. Objective structured assessment of technical skill (OSATS) for surgical residents. Br J Surg 1997;84:273-8. 